\title{
Enacting inclusivity in the preparation of emerging scholars
}

A response to programme reform in higher education

\author{
Saran Stewart, Chayla Haynes, and Kristin Deal
}

\begin{abstract}
This article explores how three doctoral candidates enrolled in the discipline of Higher Education gained an understanding of social justice, equity-mindedness and diversity in the academy. Prior to the admission of these three students, two faculty members had reformed the doctoral programme to align it with the principles of inclusive pedagogy. They created a conceptual framework for the redesign of the programme's mission, curriculum and pedagogy. Echoing an article that those faculty members wrote about the programme, the authors use a collaborative autoethnographic approach to share their experiences of the programme. Just as the faculty members engaged in a fictitious dialogue with their source of inspiration, bell hooks, the authors engage in a conversation with the programme chair about their pursuit of education as the practice of freedom.
\end{abstract}

\section{KEYWORDS}

collaborative autoethnography, diversity, doctoral education, equitymindedness, higher education, inclusive pedagogy, programme reform

In the fall of 2010, the authors enrolled in a doctoral programme in educational studies that focuses on higher education (HED) as a discipline at the University of Denver. The programme had undergone a self-initiated redesign two years earlier, and at that time, the programme leaders Frank Tuitt and Mary Ann Danowitz were writing an article (see Danowitz and Tuitt 2011) about their approach to restructuring the HED doctoral programme. They described how they used Inclusive Pedagogy (Tuitt 2003) to guide their thinking about fostering critical consciousness in the scholarly identity development of doctoral students. Towards the end of the article, Tuitt shared a personal 
narrative of a fictional conversation he had with bell hooks centred on two main questions, ' 1 . What is my responsibility as a teacher related to teaching in a manner that respects and cares for the souls of my students? 2 . What are my students' responsibilities related to engaging in education as a practice of freedom?' (Danowitz and Tuitt 2011: 49).

In an effort to assess how those questions have been addressed in the programme revision, we pose two central research questions: (1) How has the programme reformation (mission, curriculum, and pedagogy) influenced the ways we experienced inclusive pedagogy in a manner that shaped and prepared our understanding of social justice, equity-mindedness, and diversity in the academy; and (2) what are our 'responsibilities related to engaging in education as a practice of freedom' (Danowitz and Tuitt 2011: 49)? We use collaborative autoethnography to share our experiences and revisit the article that inspired this study to engage in a dialogue with Professor Tuitt about our pursuit of education as the practice of freedom. What follows in the next section is a discussion of the study's guiding framework and setting.

\section{Inclusive pedagogy: Guiding framework}

Danowitz and Tuitt's research (2011) used Inclusive Pedagogy to guide their redesign of the University of Denver's higher education programme. 'Inclusive Pedagogy' as developed by Tuitt (2003) for the discipline of higher education refers to the practice of teaching and learning for the development of inclusive learning environments for all students, especially racially minoritised students. The programme leaders, Danowitz and Tuitt, started the redesign by revising the programme mission to centre on social justice and diversity. Several significant curricular changes followed to align course goals and learning objectives with the new programme mission. Moreover, teaching methods and learning activities were also rethought to prompt HED students to interrogate the course material through the lenses of 'power, inequality, race, ethnicity, class, and gender' (Danowitz and Tuitt 2011: 47). Danowitz and Tuitt revealed in their article that the use of personal narratives was one teaching tool that helped students interrogate their own biases and assumptions. These narrative assignments often took the form of self-reflexive journals that would juxtapose our lived experiences with our understanding of the weekly assigned readings.

Along with the curriculum changes, all courses would address diversity in meaningful and real ways by adopting a Freirean (2010) philosophy, which 
understands education as a locus for social and political change. All courses adhered to inclusive pedagogy, a reflexive and critical educational approach, which helped students experience education as a liberatory act (Danowitz and Tuitt 2011). From this framework, we explored how the reformation of the programme impacted our socialisation during and after our first year as doctoral students.

Notably, Tuitt (2003) combined multiple taxonomies of critical pedagogies to develop Inclusive Pedagogy as a teaching and learning framework. It originated as a 'term that advocates teaching practices that embrace the whole student in the learning process' (243). Tuitt (2003) refers to the holistic development of the student and the use of inclusive pedagogy to develop not only the minds of students but their socio-emotional characteristics. The term originally had five tenets: faculty-student interaction, sharing power, dialogical professor-student interaction, activation of student voice and utilisation of personal narratives. Since 2014, these have evolved into a framework that includes additional principles of critical and inclusive pedagogies to combat the current volatile climates on campuses (see Tuitt et al. 2016). The tenets of Critical and Inclusive Pedagogies (CIP) draw upon paradigms and theoretical models that promote liberation and critical consciousness (e.g. Freire [1970] 2010). For example, Tuitt et al. (2016) highlight that CIPs help students personalise the subject matter by modelling for them how to make connections between the concepts under study and their lived experiences. Also, CIPs demonstrate an understanding that the classroom/content is not race-class-gender-sexuality neutral by making pedagogical decisions that centre on students' intersectional and multiple identities. Additionally, CIPs employ interactive and dynamic teaching practices that position students as 'knowers'. It further utilises diverse and interdisciplinary content that disrupts dominant viewpoints and narratives. Finally, CIPs are courageous, transparent and equity-minded because they engage in the self-work of developing critical consciousness and evaluating its influence on faculty behaviour. In this article, we demonstrate how our experiences as doctoral students informed by a CIP lens inspired our pedagogical training and research interests as first-year faculty.

By the time we entered the programme in 2010, these changes were cemented in practice, and we were the first cohort to experience the revised programme in its entirety. Professor Danowitz had relocated to Europe and Professor Tuitt remained as the programme director who taught the core 
foundation courses throughout the first academic year. For all three of us, he also served as our doctoral dissertation advisor.

\section{Methodology}

At the end of our first academic year, we met to discuss potential publications emerging from our course work, in particular our self-reflexive journals, autobiographical papers and analytical memos. There started the first draft of this current manuscript. We employed collaborative autoethnography 'a qualitative research method that is simultaneously collaborative, autobiographical and ethnographic' (Chang et al. 2013: 17) - to explore how we experienced inclusive pedagogy in a manner that shaped and prepared our understanding of social justice, equity-mindedness and diversity in the academy. We examined a variety of written and audio-visual assignments we completed during our first year in the doctoral programme. The assignments reflected the tenets of inclusive pedagogy and in particular the use of selfreflexivity as a conduit to do the critical self-work needed in the academy. Modes of data included the following:

1. Three 12- to 15-page educational autobiographies and accompanying audio-visual presentations in which we used theory to reflect on and analyse lived educational experiences.

2. Numerous analytic briefs where we engaged in the reflection and synthesis of weekly readings and personal experiences. All briefs were taken from the restructured courses.

3. Three final projects aimed at helping us translate theory into practice and 'become more engaged in research for the public good' (Danowitz and Tuitt 2011: 51).

4. Recorded, open discussions about our experiences as first-year students and our preparation as emerging scholars.

We treated these data as transcripts of our learning and engagement within the higher education doctoral programme. After individual initial coding, we met to examine the similarities and differences from within and between codes in our first round of data analysis. In the second phase of data analysis we established themes to illustrate how inclusive pedagogy shaped both our individual and shared experiences of the HED doctoral programme. 


\section{Positionality}

As our social identities shaped our experiences within the HED doctoral programme, it was important to acknowledge the complexity of these identities and their influence on our abilities as both researchers and participants. Geographically, we hail from various shores - California, Washington, DC, and Jamaica - resulting in varied nationalities and educational histories. Racially in the United States, we identify as White American, Black American, and Black Jamaican, further problematising our lived experiences and entrance into this doctoral programme. Though we all identify as cis-gender women (i.e., our personal identity and gender aligns with our biological sex at birth), we bring with us into this study our varied religious identities and familial structures.

\section{Findings and discussion}

To be true to both the method of collaborative auto-ethnography, as well as to our individual journeys, this section consists of our findings as detailed by each author, however collectively analysed and written together. We argue that, due to the pronounced mission and goals of the programme, our overarching experiences mirror each other, moving towards education as an act of freedom.

\section{Kristin's lessons}

After five years working in the field of higher education, I decided to pursue a doctoral degree in preparation for administration. Ultimately, I chose to apply to and attend this specific programme due to the emphasis on diversity and the scholarship produced by the faculty. As I examined my writings from the last year, three themes emerged: (1) performance, (2) (re)visibility of power and privileged structures, and (3) the confluence of guilt and hope towards ownership and accountability.

In my initial writings from my first quarter as a doctoral student, I relied heavily on theory as a method of processing the work of inclusion. These writings engage with the philosophies of Paulo Freire (2010) and bell hooks (1994). Reading these writings, I can experience my desire to pass as intelligent enough to be a doctoral student and enlightened enough to be a social justice ally. Noting the mission of the programme and my place within my 
cohort as a white woman, these first papers seem now to be a performance of what I perceived as characteristics of a good student and, as Audrey Thompson (2003) might suggest, a good white person. My assumptions of my own levels of privileged consciousness are apparent. At the end of my first reflection, I asserted that during my college years, I had established a 'self-actualised understanding of education', which meant that education could enable a person to reach their full potential (Kristin, journal entry, 2010). Ten weeks after my initial reflection in this same class, I concluded, 'If education is meant to be an act of liberation, then self-actualisation is not the end goal. It is a mere point along the continuum, and I am reminded that there is still work to be done, professionally and personally. There are still many things I have yet to learn’ (Kristin, journal entry 2010).

As I moved away from thinking of myself as self-actualised, the notion of visibility became increasingly prevalent. This theme occurred at both the personal and systemic level. As there seemed less need to perform, my writing turned towards making visible the underlying structures that allow for and maintain white privilege and power and my place as a beneficiary. Courses challenged me to move beyond the often nebulous and theoretical conversations about power and oppression and instead to personally wrestle with the tangible assets I garnered in the inequitable system. In our educational autobiographies, we were required to utilise an analytical lens provided by course readings and intertwine them with our personal educational narratives. Recounting my personal memories living in the suburbs of Los Angeles during the riots of 1992, it is easy to see the movement of visibility from the structural level to the personal level:

Doors [in my hometown] were locked and people began to look over their shoulders in fear of flying bricks. Democracy as the freedom to pursue life, liberty, and happiness became shallow, individualistic, and temporal. Fear of the other, with little acknowledgement of the larger systemic reasons for the riots, truncated democracy, centering [on] the safety of my life, the protection of $m y$ liberty, and the pursuit of my happiness. (Kristin, journal entry 2010)

What derived from the visibility of my power and privilege was a need for a new understanding of the confluent nature of guilt and hope. I worked to balance the naming of my space as a privileged person in society and naming the impacts of that privilege on society. My work and my research began to 
consider the need to hold guilt and hope in tension and in communion with one another. In one of our courses, Professor Tuitt asked that we write a reflection on hope, forcing me to reconcile my whole self with the topics of the course. In my reflection, I see the need for hope alongside the existence of guilt.

For me, it [the Lenten season] exemplifies all that I believe in, that I live currently among dark days but with the hope for brighter ones to follow. It is thus a time of anticipation, of living in the paradox of 'now and not yet'. Of learning to find joy in the realized justices, mercies, and changes that we have witnessed and can look back on to find solace, without losing sight that there is still much work to be done, many fields still to labour in [hooks 1994]. While on the other hand, longing and hoping for what is yet to come, without losing heart in my current location. This for me is the paradox of hope. (Kristin, journal entry 2010)

These notions resulted in ownership and accountability. In response to $\mathrm{Dr}$ Tuitt's call to action statement, 'we need you to hope', I name my place among those he and hooks (1994) called to join in the work of education-asan-act-of-freedom. I reply by saying:

I am the 'you' who must choose, albeit some days with a weak and strained voice, to speak out against the oppressor. . . I I am the 'you' who must choose to protest, albeit some days with little fervour and less assurance, for the toppling of the master's house. I am the 'you' who must choose to remember hope, to exist in hope, to live fully in this time of anticipation, both in the now and not yet. (Kristin, journal entry 2010)

As part of ownership, after a year in the doctoral programme, I decided that rather than return to administration, I want to pursue a career in the professoriate. In particular, I want to work with young practitioners to critically analyse their identities, with the hope of moving towards a critical consciousness that purposefully engages in the work of equity.

\section{Chayla's socialisation}

I entered the programme after ten years as a student-affairs practitioner to enhance existing skills and advance others in the aspiration of becoming a faculty member. The analysis presented a set of four interwoven themes: 
performing, double consciousness, reconciliation, and renewal and accountability. Together, I refer to this process as socialisation by way of a personal excavation. I use the term excavation to illustrate the way my socialisation to this programme and the scholar role involved exposing a superficial exterior to reconnect to my authentic self. Borrowing from Cranton and Carusetta's (2004) study on the five dimensions of teacher's authenticity, I identify with my need to connect to better forms of self-awareness, relationships with learners, and a reflective approach to practice. Until this point, I remained fragmented, learning how to operate out of only one dimension of my identity instead of drawing on the strength of an integrated identity.

Our first weeks were full of course discussions and readings that integrated theory and research, reflecting a transformative and inclusive learning process. We covered topics and concepts I believed I already knew about. This notion was reinforced in my writing. In one of my reflections on inclusive pedagogy, I evaluated the types of learning environments that have been both conducive and unfavourable in the facilitation my own learning by concluding, 'Our collective success as educators is dependent on each person's willingness to participate fully in the learning process, commitment to creating learning communities that foster reflection and cognition, and recognition that inclusive pedagogy enhances both the teacher's and student's ability to live life more fully and deeply [hooks 1994]' (Chayla, journal entry 2010).

Yet, had I ever really been able to participate fully in the learning process; and thereby live deeply? Instead of drawing conclusions from my own experience, I was performing toward perceived expectations of what an educator should know, ought to believe, or must value. In subsequent writings, I considered the 'bevy of contradictions' that graduate work has forced me to sort out, as I explored the function of research, its relationship to the scholar role, and its influence on my educational path.

It was in the exploration of these contradictions, that the second theme, double consciousness, took shape. Double consciousness represents a dichotomous identity between how I view myself as a student versus as a scholar. As I reflected on my increased understanding of the scholar role, I observed incongruence between my understandings of what education should be and my own experience within it. Borrowing from W. E. B. Du Bois' (1903) explanation of double consciousness, I began to realise the inherent conflict that existed when aligning myself with an educational system that never fully recognised me. This theme is best illustrated in the excerpt from this analytic 
brief: 'Despite being a self-identified educator and consummate learner, I view the majority of my formal educational experiences (both as student and scholar) as racialized. To be honest, maintaining active participation in a system that rarely accounts for or values my presence is difficult and requires a daily process of forgiveness, renewal, and recommitment' (Chayla, analytic brief 2011).

Reconciliation was first introduced in a class dialogue. A major component of the curriculum included the formulation of an educational autobiography. It was apparent to Dr Tuitt that I was struggling with this assignment, as I was having difficulty intellectualising the breadth of emotions this particular assignment precipitated. With uncensored honesty, I shared with the class that I found it challenging to present my experience without addressing how my understanding of these concepts are grounded in my identity as a Black person and a Christian, which have remained isolated from my professional identity. In response, Dr Tuitt encouraged me to incorporate the sum total of who I am into my identity as a scholar. Then, and only then, would I truly draw on the source of strength that exists within me. I began to seek wholeness of self through the process of reconciliation. This allowed me to see the strength and power of aligning my multiple identities, as demonstrated in this excerpt on hope:

I can say with confidence that my participation in this programme is stretching my faith. By this I mean that I pray daily and repeatedly seek wisdom, for things that I don't understand, forgivingness for judging others and for carrying discontent in my heart, and peace to rid me of insecurity and fear. I share this publicly not as a means of seeking empathy, but rather as an acknowledgement of how my participation in this programme, this educational system, this learning environment is transforming me for the better. I like who I am today and long for what God desires me to be. And the best thing about this experience is that I don't share in it alone. (Chayla, journal entry 2010)

The final theme that emerged was renewal and accountability. By renewal, I am attempting to describe the commitment to education that I established, grounded in my own experience as a student and a scholar. I begin the renewal process by evaluating my role and possible contributions to the institution of education and how it has continued through the establishment of accountability, making both the academy and myself liable for the learning process. 
Despite being a racialized environment, I do believe that the institution of education is well positioned to address and redress the social and racial injustices that have and continues to dismiss the needs of people of colour. The larger challenge for me, as a participant in and advocate of education, is how I break the cycle and illuminate discriminatory practices that permeate the racialized system of education?

It wasn't until recently that I came to view my participation in the system of education (both as student and scholar) in this manner, as opposed to viewing education and my participation as a mammoth obstacle with no hope of change. My desire to participate in the production of research that presents counter-narratives and oppositional discourses of people of colour, rejecting the perpetuation and acceptance of practice, policies, and discourses based on racial bias has only been cemented. (Chayla, journal entry 2010)

The renewal process becomes crystallised through my use of counternarratives and the need to contribute to academic discourse for and by scholars of colour. This theme disrupts the status quo production of knowledge by predominantly White and Western scholars and calls for scholars of colour to produce knowledge and oppositional discourses in the academy that are more representative of communities of colour.

\section{Saran's understanding}

Combing through the briefs and papers I wrote during my first year, I catch myself snickering at my comments and in awe of my progression from start to finish. I interpreted and coded for two salient re-emerging themes: (1) identity development, formation and transformation, and (2) hope in the unseen.

\section{Identity development, formation, and transformation}

'Black. Mother. Jamaican. Scholar.' The first line of the first paragraph in my first reflection contained those four salient identifiers. I entered this process seeing myself as a Black mother from Jamaica who aspires to one day be a scholar. Throughout the year, my identity oscillated, leaving me to realise that in any given space the internal and external dichotomy of seeing myself through and as the other conflicted in space and time. At the start of the fall quarter, I grappled with my acceptance into the doctoral programme: Do I belong here? Should I be here? Who am I? Having recently moved from the 
Southeast coast to the Rocky Mountain region, my sense of self in society was categorised by stereotypic profiling of being Black in a predominantly White state. I wrote in one of my reflections that regardless of my doctoral status at the university, that on the street, 'as much as I have been transformed is as much as I have remained the same, because still outwardly, I will forever remain, just another Black face, on the train, pushing a stroller, tired with glossy eyes' (Saran, journal entry 2010).

My socialisation process was unique as my purpose for the doctoral degree was innately linked to my postcolonial subjectivity. As such, my identity as a Jamaican resonated in and throughout all of my writings and impacted the lens in which I refracted my use of rhetoric and bias. Whether it was seeking 'the virtuoso freedom of expression that would allow me to be unchained from the nooses of Standard-Colonial English writing' or whether it was the positioning and repositioning of myself as a 'powerful, post-positivist, pragmatist', I constantly self-critiqued my roles in academe (Saran, journal entry 2011). Dr Tuitt would often advise to 'trust the process', but as a Black woman studying in a predominantly White institution, I questioned whose process should I trust: 'Students like ME have to make a difficult choice between advocating for MYSELF and other students of colour and the price of total exhaustion from constantly having to step into the advocacy and defence role' (adapted from Galman et al. 2010: 231). I questioned my role in the academy, in the university, in the programme, knowing that education leadership programmes 'only relegate race to a theoretical footnote within the larger discourse of educational leadership but fail to probe how issues of race intersect and permeate the educational landscape' (Galman et al. 2010: 71).

However, I am hopeful of what this doctoral process has in store for me. The trajectory of my writing culminated in the final quote, 'today I can reflect and affirmably confess that it is because of my social, political, cultural, educational capital earned in Jamaica that I possess an invaluable selfworth, where I know my past and thus know the boundless potential of my future' (Saran, journal entry 2010). Identity development, formation and transformation was a recurring theme throughout my doctoral years. The underpinning philosophy of the programme and its courses constantly demanded from me that I reflect on my purpose and rationale for entering the programme. The theme represented the socialisation process of the doctoral journey and emergence of a scholar identity. 
Hope in the unseen

I believe there is an inextricable link to my identity as a mother and the salient theme of hope in the unseen. Hope in the unseen represents the motivation and resilience needed to be both a mother and scholar in the academy. It further speaks to the hidden demands and roles of mother-scholars and the criticism mothers endure within the academy. My daughter represents hope in the unseen as she remains the embodiment of motivation and resilience. My persistence and drive to succeed in the academy are linked to my daughter one day knowing the sacrifices I made during this process - the sleepless nights and countless hours studying away from her.

In the middle of my first year, Dr Tuitt asked our class to write about hope. I responded:

Hope exists for me in two living contexts: my father and his legacy, my daughter Sekai. These two interwoven, overlapping paradigm shifts are my conceptual framework of hope. My father is Cornel West's epitome of an intellectual freedom fighter. Growing up below the poverty level in a developing country, education was his vehicle to self-actualization ... I have marched, rallied, picketed, read, written, and voiced complaints, argued, shouted and contested ignorance, but I have never taught from example until I was conscious of my most impressionable pupil - my daughter. I recognize her as spring's first bloom; representing life, like the first cherry blossoms in March. She reminds me that we (my classmates and I) are all born innocent and unknowing into this world and if we are asked to become agents of change for social, cultural and political issues, we must possess the willingness to hope for change. I will be an intellectual freedom fighter, in context, belief and action. My daughter will know from example, as I have known, that change can start from the inner ghettos of Kingston, Jamaica, with simply a mere glimpse of hope. (Saran, journal entry 2011)

Hope in the unseen represented multiple layers of trusting the process of the programme and remaining resilient in balancing the demands of being a student and a mother. The constant demand to stay motivated to complete the programme while nursing a sick child or being reconciled to two hours of sleep per night was reified in the theme. 


\section{Conversation with Dr Tuitt}

Inspired by the fictional conversation with bell hooks in the article by Danowitz and Tuitt (2011), our aim in this section is to revisit a conversation we had with Dr Tuitt after our first year in the doctoral programme. This conversation considers the manifestation of critical consciousness an outcome of the mission, curricular and pedagogical changes of the programme. The dialogue below revolves around the answers to two major questions: How has the programme reformation (mission, curriculum, and pedagogy) influenced the ways we experienced (1) inclusive pedagogy in a manner that shaped and developed our understanding of social justice, equity-mindedness and diversity in the academy; and (2) what are our 'responsibilities related to engaging in education as a practice of freedom' (Danowitz and Tuitt 2011: 49)?

\section{Mission}

In our first class, you took a moment to reassure us that had the faculty not thought we were ready for this journey, we would not have been accepted into the programme. Your engagement with the often-felt imposter syndrome helped to ease some of our initial fears; it did more than that. Our anticipatory socialisation (Weidman et al. 2001) had started much earlier than that moment in class, and your affirmation of our space reinforced not only a belief in our intellectual prowess but in our ability to take up the mission of the programme and become freedom fighters and freedom writers. As we moved through that first quarter, your purposeful pedagogical approach to engage us more deeply in the mission of the programme through reflective writing aided in the internalisation and amalgamation of our new professional identities with our existing concept of self.

\section{Curriculum}

Reformatting the programme, with the integration of social justice education throughout the curricula, required us to be active participants, bringing our whole selves into the classroom. The programme forced us to consider our assumptions and critically analyse the identity dimensions of 'race, ethnicity, religion, disability, class', within the field of education (Danowitz and Tuitt 2011: 47). In reference to the required educational autobiography, you wrote that, 'as students gained awareness of the meaning of growing up as a 
black, biracial, or white girl or boy, this provided an important opportunity for students to learn about intersectionality' (Danowitz and Tuitt 2011: 47). We go further and say that this piece of writing challenged us to situate ourselves in the educational discourse and put aside espoused but not yet realised values of education. It forced us to think critically about the work that remains undone, our roles as perpetrators of the status quo, and our obligation to those who remain behind.

The required courses and content moved us daily to seek responsibility and opportunity in the field of our choosing. These shifts shaped our learning and continue to shape our 'research, leadership, advocacy, and practice in higher education' as we continue to harness 'a social justice paradigm that focuses learning on both disadvantaged populations and the systematic structures of oppression (both social and academic)' in order to develop 'a commitment to the deconstruction and disruption of such structures' (Danowitz and Tuitt 2011: 48).

\section{Pedagogy}

Your use of inclusive pedagogy gave us a platform on which to stand and standards to meet as we learned to bring our whole selves into the classroom. Through your transparent and vulnerable teaching, our socialisation process became both formal and informal (Weidman et al. 2001), allowing us to take ownership of our lived experiences, while preparing for the realities of being engaged pedagogical scholars. You modelled 'personal engagement with radical and transformative perspectives', reminding us of the importance of interrogating '[our] existing beliefs, values, and worldviews' (Danowitz and Tuitt 2011: 49). And by leveraging our personal and shared experiences and understandings, we experienced levels of investment and trust within the learning community.

\section{Our responsibilities: Those things gained and those things lost}

Besides loss of balance, time, sleep and 20-20 vision from being full-time doctoral students, we have also experienced a loss of our former selves. Through reflection on our location in the mission and our experiences with the curriculum and inclusive pedagogy, we were forced to consider our selfishness within this work. Reflected in colour-blindness, naive hope or disenchantment with the field, our relationship with education took on new forms of 
accountability towards a realised critical hope (Duncan-Andrade 2009). We now recognise that there is no excellence without self-work, self-reflection, self-critique and self-renewal.

In the end, we have each experienced education as an act of freedom. We have 'rejected learning for learning's sake and instead embrace the idea that education should be used for social and political change' (Danowitz and Tuitt 2011: 49), which resulted in personal reconceptualisation and recommitment to becoming educators for freedom. The three authors summarise what we gained as follows:

I believe that education is a form of freedom and, from a developing world identity, the accession to upward social mobility is almost always synonymous with attaining an education. Growing up in Jamaica, there was never a question about the value of education as I am legacy of where education can take you - from literally horse stable homes to homes on the hills and just because of education. (Saran, educational autobiography 2011)

My liberation through education accompanies the loss of liberation by ignorance afforded to me by the very colour of my skin. In exchange for learning to daily confront and forfeit the unearned power of my privileged space, I work to become one in the lineage, even if only by metaphoric adoption, to those that have gone before me in this struggle for equity. In this, I find freedom. (Kristin, educational autobiography 2011)

When and at any other time in my educational career have I felt that what I experienced was worthy of scholarship? I grew up believing that nothing I had to offer is worthy of becoming part of the cannon of scholarly literature. As students, we are expected to participate in the co-construction of knowledge in the classroom and that in my mind is what makes the learning process liberating. I no longer have to adopt or perform toward someone else's standard of excellence. (Chayla, educational autobiography 2011)

\section{Implications and conclusion}

Even when intentionally studied and deconstructed, engagement with inclusive pedagogy to develop social justice consciousness, equity-mindedness and diversity requires continuous self-work on the part of the doctoral students and faculty. As such, we offer a few points of consideration for programme coordinators or faculty chairs as they consider engaging in inclusive pedagogy. 
First, though the development of a scholar-identity is an individual experience, it is important for faculty to engage students in considering and interacting with the explicit academic/learning outcomes, as delineated in the programme mission where Inclusive Pedagogy is an embedded principle of the mission.

Second, curriculum is most often used to assess a student's learning and engagement with course content. The location of curriculum as a site for engaging the whole student (mind, body and soul) is frequently unrecognised, furthering the banking system of education (Freire 2010). Rather, faculty members can harness the lived experiences of their students towards the realisation of the programme mission. Assignments, readings and group discussions thus become locations where social justice education is collectively and collaboratively experienced, rather than simply analysed by the student and taught by the professor. Additionally, the use of all aspects of the curriculum towards establishing a social justice paradigm forces students to move beyond the othering nature of diversity education and instead engage their own assumptions, privileges and histories in conceptualising their ability to become change agents. When coupled with an explicit social justice mission, the curriculum becomes the place where students critically engage in their formal socialisation by utilising their personal experiences to inform, interrogate, critique and challenge various theories and epistemologies.

Third, both a mission and curriculum aimed at social justice education will fail to produce scholars and practitioners critically committed to and engaged in the work of equity, unless it is anchored in a purposeful and thoughtful use of inclusive pedagogy. Inclusive pedagogy is the avenue for fostering student ownership of the learning space, while at the same time modelling a vulnerability that challenges students to bring their whole selves to the classroom. This is possibly the most difficult of the three points highlighted here because it requires faculty members to have already done and be committed to the continual self-work needed to enter the classroom space as facilitator, co-learner and colleague in the movement of equality. Faculty must be willing to leverage their own personal experiences and reactions as example, modelling for students the careful negotiation between theory and practice.

The findings of this study provide faculty and administrators with ways of conceptualising how Inclusive Pedagogy as a framework when embedded within the mission, curricular and pedagogical changes can be made to enhance student learning and development, while preparing them for the 
changing needs of the academy and its constituents. These findings are of particular significance to graduate programmes in higher education, as they discuss the use of inclusive pedagogy through the utilisation of Freirean (2010) philosophy and engaged pedagogy (hooks 1994) to harness student learning and development towards education as a practice of freedom. Such purposefully tailored programmes aid in reaching historically underrepresented students and provide culturally inclusive experiences, supporting these students in persistence through to graduation. With a stated mission and detailed curriculum towards the advancement of inclusivity and by utilising inclusive pedagogy, graduate programmes will attract more diverse applicants, enhancing the classroom environment and better preparing all students to be faculty members and/or practitioners uniquely trained and deeply committed to the mission of equity.

Saran Stewart is a Senior Lecturer of Comparative Higher Education in the School of Education and Deputy Dean for the Faculty of Humanities and Education at the University of the West Indies, Mona Campus, Jamaica. She was awarded the 2018 African Diaspora Emerging Scholar by the Comparative and International Education Society. At the core of her research, Dr Stewart, uses a variety of social science methodologies to critically examine issues in comparative education, postcolonial theories, critical/inclusive pedagogy, decolonising methodologies and access and equity issues in higher education. Her work has been published in the Journal of Diversity in Higher Education, Journal of Student Affairs, Postcolonial Directions in Education Journal and the Applied Anthropologist Journal, among others.

Email: saran.stewart@uwimona.edu.jm

Chayla Haynes joined the Educational Administration and Human Resource Department at Texas A\&M University in 2016 and is a critical qualitative researcher who explores issues of power and powerlessness through the scholarship of teaching. Among her numerous publications are two co-edited books, Interrogating Whiteness and Relinquishing Power: White Faculty's Commitment to Racial Consciousness in the Classroom (Peter Lang Publishing) and Race, Equity, and the Learning Environment: The Global Relevance of Critical and Inclusive Pedagogies (Stylus Publishing). In 2016, the American College Personnel Association named Dr Haynes a 2016 Emerging Scholar Designee. Email: chayla.haynes@tamu.edu 
Kristin Deal is Director for the Office of Diversity and Inclusion, as well as an adjunct professor of Higher Education at the Morgridge College of Education at the University of Denver. Her research and teaching interests include social justice in education, race and racism in educational policy/practice, critical whiteness theories, critical emotionality studies and the possibilities of change when emotion and social identity are engaged in educational spaces.

Email: Kristin.Deal@du.edu

\section{References}

Cranton, P. and E. Carusetta (2004), 'Perspectives on authenticity in teaching', Adult Education Quarterly 55, no. 1: 5-22. doi:10.1177/0741713604268894.

Chang, H., F. Ngunjiri and K. Hernandez (2013), Collaborative Autoethnography (Walnut Creek, CA: Left Coast Press).

Danowitz, M. A. and F. A. Tuitt (2011), 'Enacting inclusivity through engaged pedagogy: A higher education perspective', Equity and Excellence in Education 44, no. 1: 40-56. https://doi.org/10.1080/10665684.2011.539474.

Du Bois, W. E. B. (1903), The Souls of Black Folks (Chicago: McClurg and CO.).

Duncan-Andrade, J. M. R. (2009), 'Note to educators: Hope required when growing roses in concrete', Harvard Educational Review 79, no. 2: 181-194. https://doi.org/ 10.17763/haer.79.2.nu3436017730384w.

Freire, P. [1970] (2010), Pedagogy of the Oppressed (New York: Continuum).

Galman, S., C. Pica-Smith, and C. Rosenberger (2010), 'Aggressive and tender navigations: teacher educators confront whiteness in their practice', Journal of Teacher Education 61, no. 3: 225-236. https://doi.org/10.1177/0022487109359776.

hooks, b. (1994), Teaching to Transgress: Education as the Practice of Freedom (London: Routledge).

Thompson, A. (2003), 'Tiffany, friend of people of colour: White investments in antiracism', International Journal of Qualitative Studies in Education (QSE) 16, no. 1: 7-29. https://doi.org/10.1080/0951839032000033509.

Tuitt, F. A. (2003), 'Afterword: Realizing a more inclusive pedagogy', in A. Howell and F. A. Tuitt (eds), Race and Higher Education: Rethinking Pedagogy in Diverse College Classrooms (Cambridge, MA: Harvard Educational Review), 243-268.

Tuitt, F., C. Haynes and S. Stewart (eds) (2016), Race, Equity and the Learning Environment: The Global Relevance of Critical and Inclusive Pedagogies in Higher Education. (Sterling, VA: Stylus Publishing).

Weidman, J. C., D. J. Twale and E. L. Stein (2001), Socialization of Graduate and Professional Students in Higher Education: A perilous passage?, ASHE-ERIC Higher Education Report 28, no. 3 (Washington, DC: The George Washington University). 